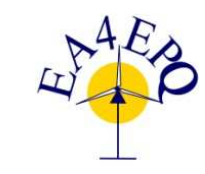

$18^{\text {th }}$ International Conference on Renewable Energies and Power Quality (ICREPQ'20)

Granada (Spain), $1^{\text {st }}$ to $2^{\text {nd }}$ April 2020

Renemable Eenergy, and Pemer Qunliily, Yournal (RE\&PQJ)

ISSN 2172-038 X, Volume No.18, June 2020

\title{
Modelling of Energy Recovery in Electric Vehicles for Various Braking Scenarios on Changing Road Surfaces
}

\author{
Valery Vodovozov and Zoja Raud \\ Department of Electrical Power Engineering and Mechatronics \\ Tallinn University of Technology \\ Ehitajate tee 5, 19086 Tallinn (Estonia) \\ Phone:+372 6203694, e-mail: valery.vodovozov@taltech.ee
}

\begin{abstract}
Due to great braking energy losses caused by traffic jams, changing velocity, and frequent start-stop modes, recovery of braking energy has become a top priority. In this paper, the universal braking system is described that operates at various driving scenarios including smooth braking and emergency antilock braking on different road surfaces and integrates both the friction and the electric braking strengths. The vehicle model reflects multiple factors, such as air resistance, road slope, and variable friction. The refined tire model recognizes changing road surfaces at different velocities. In the motor and battery model, the state of charge and electric current/voltage restrictions of the hybrid energy storage are taken into account. Braking torque generated by the Sugeno's fuzzy logic controller established in the Simulink environment is allocated between friction and electric brakes. Often cited torque oscillations at low vehicle velocities have found their description, being reduced and evenly distributed throughout the braking process with the help of torque stabilisation loop. The outcomes of this study can be considered in the design of braking systems for electric vehicles with superior energy recovery capacity.
\end{abstract}

Key words. Electric vehicle, energy recovery, recuperative braking, hybrid energy source, antilock braking system.

\section{Introduction}

Development of control systems for road electric vehicles (EV) features many new approaches aimed at energy saving enhancement. As from $25 \%$ [1] to 50\% [2], [3] and even up to $70 \%$ [4] of the driving energy is lost during frequent speed change and vehicle braking, the braking energy recovery could reclaim this loss and extend driving range. Consequently, implementation of advanced blended braking systems (BBS) has become a top priority and intensively moves forward. Such systems unite traditional friction braking (FB) with recuperative electric braking (EB) machinery which, in turn, is linked with hybrid energy storage (HES) equipment combining both the high energy density modules (batteries) and the high power density blocks (ultracapacitors or/and flywheels) [5]. BBS have attracted attention in science and industry also because of reducing vehicle maintenance costs and emission of tire particles.
Most of EV system designers, such as [6], [7], prefers EB for vehicle gradual slowing down and FB for heavy braking. EB is commonly out of use in the antilock braking system (ABS) and is not applied as an urgent braking tool because the force generated by an electric motor is often rather small to produce total braking torque needed to ensure vehicle stability at heavy stopping [1]. Additionally, EB fails due to battery overheating and state-of-charge (SOC) restrictions.

When braking torque distribution in BBS is discussed, three approaches fall to the focus of attention: unequal force assignment between right and left wheels, fair power sharing among front and rear wheels, and smart torque allocation between EB and FB systems. The last issue aims to acquire maximal braking energy from both $\mathrm{EB}$ and $\mathrm{FB}$, to ensure the highest recuperation capacity, and to engage EB in the best way [7]. At that, ABS occupies a special place and usually represents the separate EV part, because its primary target is braking distance and time reduction.

Most of ABSs badly operates in fragile and unclear driving conditions because of their setting to high-speed driving on the straight dry roads. As a result, when rain, snow, or loose gravel appears, ABS may prolong braking instead of reducing due to improper control arrangement. To resolve the problem, intelligent slip-adjusted ABSs were proposed in [5], [6]. Thanks to the fuzzy logic controller (FLC), the most progressive of them evaluate a priori unknown changing tire properties, road surfaces, and vehicle deceleration taking into account the displacement and rate of the brake pedal pressing, the vehicle speed, and the slip rate error as FLC inputs [8]. Nevertheless, these references exclude application of EB in $\mathrm{ABS}$ and separate $\mathrm{ABS}$ from the common braking system. Usually, while the braking demand is small, EB operates, but as the ABS is requested, FB is applied [9].

Just like in the initial part of this research published in [10], this study is devoted to arrangement of the HESoriented BBS suitable for different braking modes at various road surfaces and velocities. However, new factors are taken into account now aiming to increase energy recovery. First, instead of the simplified method 
of the tire-road friction estimation by means of vehicle acceleration, the refined friction model reflects here multiple factors, such as air resistance, road slope, and rolling friction. Second, in addition to ABS, the offered braking system can operate in both the smooth and the heavy braking modes. Third, instead of the common firstorder transfer function, the detailed model of electric drive operated in the torque control mode is used in simulation.

The problem of braking control arrangement is formulated as seeking among the three actions: nonelectric braking, smooth braking with recuperation, or heavy braking, including $\mathrm{ABS}$, with maximal $\mathrm{EB}$ involvement. The research objective is to enable energy recovery by achieving maximal recuperation in all scenarios. In the following sections, the detailed vehicle model, the tire model, the motor and battery model, and the versatile braking controller are described and their performance is explained. Then, the FLC is designed and electromechanical simulation is conducted. Finally, experimental results are compared to the simulation outcomes.

\section{Vehicle Model}

To slow down the vehicle moving at some initial velocity $\mathrm{v}$, it is required to capture EV energy $W_{B}$ by developing rather braking power $P_{B}$ and force $F_{B}$ at efficiency $\eta$ in a given time interval $t$ :

$$
W_{B}=\eta \int P_{B} d t=v \eta \int F_{B} d t .
$$

In compliance with [11], [12], dynamics of the braking single-wheel quarter-vehicle are defined as follows:

$$
\begin{gathered}
m a=F_{B} \\
F_{B}=\square F_{\text {air }} \square F_{g}+F_{x} . \\
F_{\text {air }}=0.5 \rho C_{\text {air }} Q\left(v+v_{\text {wind }}\right)^{2} \operatorname{sgn}\left(v+v_{\text {wind }}\right) \\
F_{g}=m g \sin (\beta) \\
F_{x}=\mu m g \cos (\beta) \\
T_{B}=F_{B} r+J \frac{d \omega_{w}}{d t} \\
P_{B}=T_{B} \omega_{w}
\end{gathered}
$$

where

$m$ - quarter-vehicle mass;

$a=-\frac{d v}{d t}-$ longitudinal deceleration of $\mathrm{EV} ;$

$F_{\text {air }}$ - air friction (aerodynamic drag);

$\rho$ - air density;

$C_{a i r}$ - aerodynamic drag coefficient;

$Q$ - front area of EV;

$v_{\text {wind }}-$ wind velocity;

$F_{g}$ - climbing friction;

$g$ - acceleration due to gravity;

$\beta$-climbing slope (road incline);

$F_{x}-$ rolling/slipping friction;

$\mu$ - dimensionless friction factor;

$T_{B}$ - braking torque;

$r$ - effective radius of the wheel;

$\omega_{w}$ - angular speed of the wheel;

$J$ - moment of inertia of the wheel.

\section{Tire Model}

Estimation of overall tire-road friction is a complex challenge because friction varies with such factors as velocity, load, torque, surface roughness, tire diameter, inflation, wear, etc., and these variations are very difficult to detect. Intensive braking raises appearance of longitudinal wheel slip $\lambda[11]$, [13] defined as the relative difference between the vehicle and wheel velocities:

$$
\lambda=\frac{v-\omega_{w} r}{v} .
$$

It means, in addition to insignificant rolling friction, slipping friction, called also tire-road adhesive coefficient, heavily affects the braking process. In accordance with (7), it involves the kinetic fraction between moving surfaces (called sliding friction or dynamic friction) and the static fraction ("stiction") between non-moving surfaces. The latter one significantly exceeds its kinetic counterpart at the beginning of starting and at the end of braking. The force that prevents a tire from slipping as it rolls on the ground is an example of static friction. Even though the wheel is in motion, the patch of the tire in contact with the ground is stationary relative to the ground, so it is static rather than kinetic friction [14].

Hence, overall tire-road adhesion depends on slip at given velocity. From (2) - (6), the adhesive coefficient is expressed as the ratio of the longitudinal $\left(F_{x}\right)$ and normal $\left(F_{z}\right)$ forces acted on the wheel:

$$
\mu(\lambda, v)=\frac{F_{x}}{F_{z}}=\frac{m a \pm F_{a i r} \pm F_{g}}{m g \cos (\beta)}
$$

The knowledge of the adhesion-slip characteristics $\mu(\lambda, v)$ is needed to ensure anti-spin regulation, antilock braking, adaptive cruise control, and energy recovery. As it affects an arrangement of the braking procedure, many studies on the adhesive coefficient estimation have been produced. In [15], it is derived based on the sensor signals and vehicle geometry. In [16], the perturbed sliding mode observer is used. In literature, several models of the adhesion-slip relations may be found, such as Magic Formula model, Burckhardt model, Rill model, and others [17]. Although the factors in these models are different, the trends of curves look very similar.

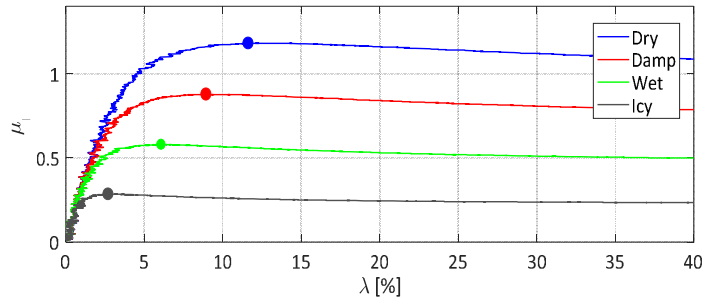

Fig. 1. Adhesive coefficient at different road surfaces.

In [10], an experimentally validated tire model based on Pacejka's Magic Formula [18] was applied to estimate adhesion at changing road surfaces. To this aim, simulation was conducted for braking from $100 \mathrm{~km} / \mathrm{h}$ on a straight lane while the vehicle decelerated under heavy braking conditions with locked wheels. According to Fig. 1, adhesion grows steeply from zero to its maximum 
appeared between 2 and 12\% slip at all road surfaces. At $0 \%$ slip, both the wheel and the vehicle have exactly the same velocities. Smooth braking operations involve low levels of slip and take place within the zone where an increase in the slip simultaneously produces an increase in the usable adhesion. Growing slopes of the curves match the stable zone where, due to the positive adhesion-slip gradient, the vehicle is suitable for control and for steerability maintenance. The peaks of the adhesion curves for every road surface are marked with dots. The falling slopes to the right of these dots emphasise the unstable zone in which the wheels may lock up inducing skidding and causing the tires to spin. When the wheel slip is $100 \%$, the wheel is locked although the vehicle is still moving.

A tire model parameterized against the real sport utility vehicle has been represented as a table of adhesion-slip data at the fixed tire load, vehicle velocity, and the most common road surfaces (i.e., icy, wet, damp and dry) and used in [10] for the road surface estimation in the designed braking controller. Naturally, given the very large uncertainty surrounding above estimates because of data incompleteness, this approach does not claim high accuracy. As the velocity decreases, the curves tend to move down and right, that is the dynamics of the wheel slip is inversely proportional to EV velocity [19], [20]. Also, such tire properties as their type, inflating pressure, etc. also change during braking, affecting the peak locations in Fig. 1.

However, from these diagrams the steerable braking condition may be confidently concluded as follows:

$$
\frac{d \mu}{d \lambda} \geq 0
$$

When $\frac{d \mu}{d \lambda}=0$, the fastest braking process is activated upon the maximal braking force.

Assuming that slip does not affect $F_{\text {air }}, F_{g}$, and considering $J \frac{d \omega_{w}}{d t}$ rather constant in the controller computational interval, expression (7) can be converted as follows:

$$
\frac{d T_{B}}{d \lambda}=r \frac{d F_{x}}{d \lambda}=k \frac{d \mu}{d \lambda}
$$

where $k=m g r \cos (\beta)$.

In turn, while braking torque $T_{B}$ follows the application torque $T$ at steerable braking, (11) can be re-written as follows:

$$
\frac{d \mu}{d \lambda}=\frac{1}{k} \frac{d T}{d \lambda} \geq 0
$$

Now, the derivative of the application torque with respect to slip may be used as a control feedback. In this way, the vehicle velocity, particularly at statics, can be included into the tire model along with other tire features, as recommended in [17], [19].

\section{Motor and Energy Source Model}

The offered system involves an adjustable electric drive integrated with FB and battery-recuperative EB. To forward the maximal fraction of actuating torque $T^{*}$ to $\mathrm{EB}$, the electric motor has to develop enough power, voltage, and current for charging all HES parts:

$$
\begin{aligned}
& P_{E \text { max }}>\max \left(P_{U C \text { max }}, P_{B A T \text { max }}\right) \\
& U_{E \text { max }}>\max \left(U_{U C \text { max }}, U_{B A T \text { max }}\right) \\
& I_{E \text { max }}>\max \left(I_{U C \text { max }}, I_{B A T \text { max }}\right)
\end{aligned}
$$

where $P_{U C \max }, U_{U C \max }, I_{U C \max }, P_{B A T \max }, U_{B A T \max }, I_{B A T \max }$ are permissible power, voltage, and current of the ultracapacitor (UC) and the battery (BAT), respectively; $P_{E \max }, U_{E \max }, I_{E \max }-$ maximal power, voltage, and current of the electric drive.

Meanwhile, to maintain the battery and ultracapacitor within their safe operating areas, the command electric current $I_{E}$ and motor torque $T_{E}{ }^{*}$ have to meet the real-time HES restrictions, namely, $S O C_{U C}$ and $S O C_{B A T}$ [5], [21]:

$$
T_{E}^{*}=I_{E} \psi=\max \left(I_{U C}\left(S O C_{U C}\right) \psi, I_{B A T}\left(S O C_{B A T}\right) \psi\right)
$$

where $I_{U C}$ and $I_{B A T}$ are the estimated charging currents of the ultracapacitor and battery and $\psi$ is the flux linkage of the electric motor.

When the actuating braking torque exceeds these restrictions, its remaining part is produced by FB:

$$
T_{F}^{*}=T^{*}-T_{E}^{*} \text {. }
$$

Therefore, the common trait of this strategy is to use the solo FB only when battery $S O C$ and voltage values are saturated.

The fewer these conditions appear, the less is waste of braking energy and reduction of the FB lifetime. In all other cases, EB is involved in both the smooth and the heavy braking processes.

\section{Model of Blended Braking System}

The main mission of the BBS is to slow down a vehicle with an application torque $T$ as close as possible to the driver's setpoint $T_{B}{ }^{*}$ without exceeding peak optimality for the road surface under the tires.

Depending on the solution selected, the fuzzy [21], PID [12], [20], sliding, and some other braking controllers compete in the market.

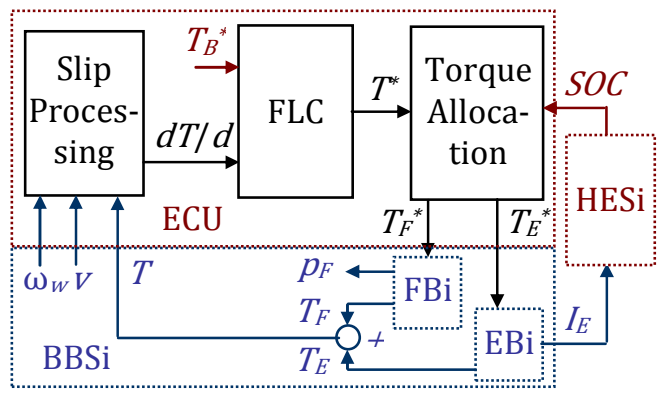

Fig. 2. The model of the EV braking system.

Based on (1) - (16), the model of BBS was designed (Fig. 2) which contains Electronic Control Unit (ECU), HES interface (HESi), and BBS interface (BBSi) comprising $\mathrm{EB}$ and $\mathrm{FB}$ interfaces (EBi, $\mathrm{FBi}$ ). ECU functionality is shared here among three stages. 
In the first one, real-time application torque $T$, angular wheel speeds $\omega_{w}$, and EV velocity $v$, obtained from BBSi are managed by the front-end Slip Processing block. Here, longitudinal wheel slip $\lambda$ (9) and application torque derivative $d T / d \lambda$ with respect to slip are calculated.

In the second stage, generation of actuating braking torque $T^{*}$ dependently of the pedal displacement (driver's setpoint) $T_{B}{ }^{*}$ and application torque derivative $d T / d \lambda$ is produced by the FLC referring to expert's knowledge due to system complexity and high nonlinearity.

Finally, the output stage algorithmically distributes actuating braking torque $T^{*}$ between front and rear wheels at a fixed ratio [21] and allocates it between FB and EB based on the real-time SOC, voltage of HES, and permissible EB current.

The demanded EB and FB commands $T_{E}{ }^{*}, T_{F}{ }^{*}$ generated by ECU are directed to the appropriate BBS interfaces. Electric current $I_{E}$ recharges HES from EB whereas the pressure signal $p_{F}$ adjusts FB. Braking will complete as the driver releases the pedal or the vehicle comes to stop.

Fig. 3 demonstrates the performance algorithm of the torque allocation stage.

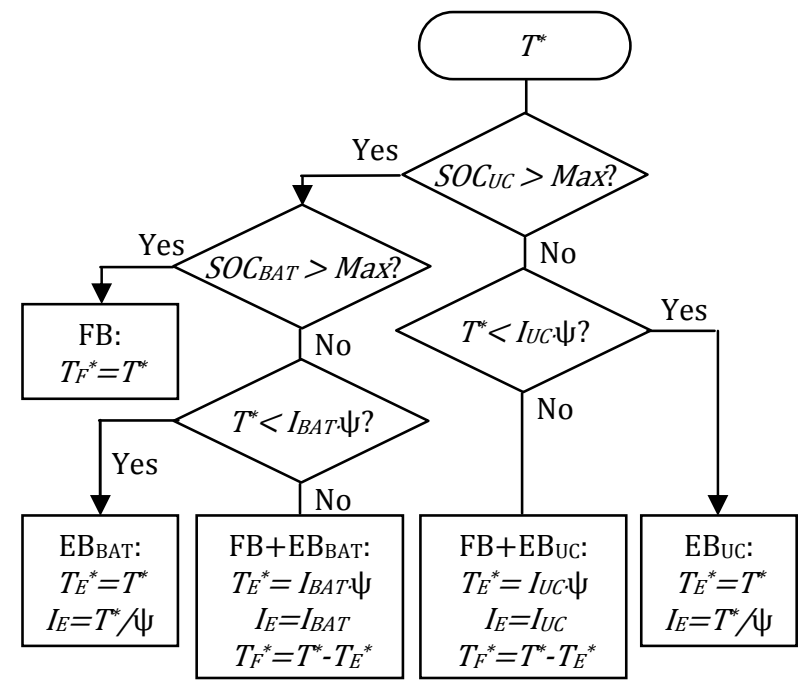

Fig. 3. Torque allocation algorithm.

Here, once ECU detects the actuating torque request $T^{*}$, $\mathrm{EB}$ is activated and either $\mathrm{EB}_{\mathrm{UC}}$ or $\mathrm{EB}_{\mathrm{BAT}}$ runs. The $\mathrm{FB}$ torque does not appear until any of $S O C$ levels exceeds permissible overcharging barriers (Max) or electric motor produces maximal power. Since motor torque becomes insufficient, the ECU runs $\mathrm{FB}$ and $\mathrm{EB}$ together $\left(\mathrm{FB}+\mathrm{EB}_{\mathrm{UC}}\right.$ or $\left.\mathrm{FB}+\mathrm{EB}_{\mathrm{BAT}}\right)$. In the case when both $S O C$ levels overcome their boundaries, the sole FB is used due to recuperation impossibility.

The main benefit of this algorithm is in inclusion of recuperation in all braking scenarios, even in heavy braking with ABS.

\section{Design of the Fuzzy Logic Converter}

The FLC target is to derive actuating braking torque needed for slowing down the EV inside an acceptable adhesion-slip region $\mu-\lambda$. The controller with multiple inputs and single output has been designed. Here, two input numerical variables (crisps) are used - driver's setpoint $T_{B}{ }^{*}$ and application torque derivative $d T / d \lambda$ with respect to slip $\lambda$. The Sugeno-style inference mechanism is applied to transform every input crisp into a separate fuzzy pair consisting of an element in universe of discourse and an appropriate membership function (MF). Estimated actuating torque $T^{*}$ is coming from the FLC output. Using the weighted average defuzzification method, this linguistic singleton signal is then turned back to the real-world output crisp.

The torque $T_{B}{ }^{*}$ input and torque derivative $d T / d \lambda$ input have four MFs notated as Z (Zero), S (Small), M (Middle), and L (Large). In Fig. 4, fuzzy sets for the linguistic variables are represented. The MFs have triangle and trapezoidal shapes suitable for braking management and experts training.

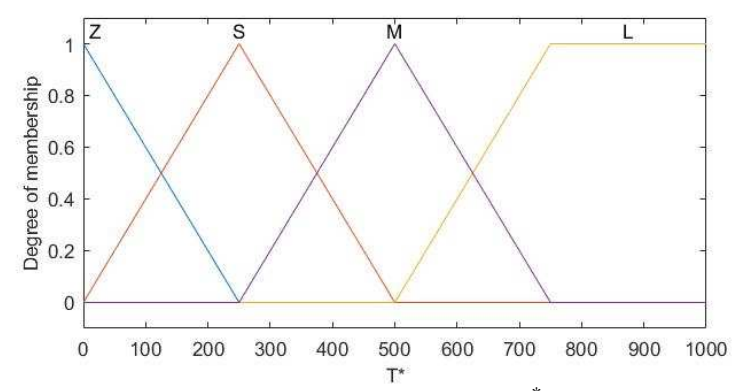

Fig. 4. MFs of control variables $T_{B}{ }^{*}$ and $d T / d \lambda$.

The inference engine with "If-Then" modus ponens converts the fuzzy input sets to the fuzzy output set using the rule base of 16 rules represented in Table I.

TABLE I. FLC RULE BASE

\begin{tabular}{|c|c|c|c|c|}
\hline Torque & \multicolumn{4}{|c|}{ Output torque $T^{*}$ at input $T_{B}{ }^{*}$} \\
\cline { 2 - 5 } $\begin{array}{c}d T / d \lambda \\
d \text { erivative }\end{array}$ & $\mathrm{Z}$ & $S$ & $M$ & $L$ \\
\hline $\mathrm{Z}$ & $\mathrm{Z}$ & $\mathrm{Z}$ & $\mathrm{Z}$ & $\mathrm{Z}$ \\
\hline $\mathrm{S}$ & $\mathrm{Z}$ & $\mathrm{S}$ & $\mathrm{S}$ & $\mathrm{S}$ \\
\hline $\mathrm{M}$ & $\mathrm{Z}$ & $\mathrm{S}$ & $\mathrm{M}$ & $\mathrm{M}$ \\
\hline $\mathrm{L}$ & $\mathrm{Z}$ & $\mathrm{M}$ & $\mathrm{M}$ & $\mathrm{L}$ \\
\hline
\end{tabular}

The resulting input-output FLC surface is plotted in Fig. 5.

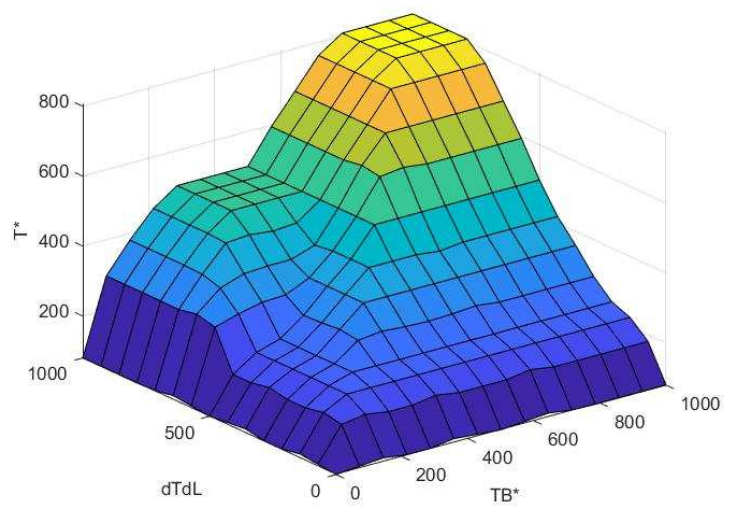

Fig. 5. Input-output FLC surface.

\section{Results and Discussion}

In the initial part of this research published in [10], the core of the offered methodology was validated with the help of the hardware-in-the-loop electro-hydraulic testbed from ZF TRW Automotive (Koblenz, Germany) driven by the vehicle-oriented software IPG CarMaker ${ }^{\circledR}$ (Karlsruhe, Germany), which ran the ABS imitator of an 
electric sport utility vehicle. Using an original FLC, that system successfully recognises road surfaces and provides blended braking.

Mass of the studied sport utility vehicle was of $2117 \mathrm{~kg}$ and wheel radius of $0.2 \mathrm{~m}$. It was assumed that the EV is moving in a straight-line manoeuvre at $100 \mathrm{~km} / \mathrm{h}$ fed by the switch-reluctance motor with maximal permissible torque of $200 \mathrm{Nm}$, speed $157 \mathrm{rad} / \mathrm{s}$, and $2.1 \mathrm{kgm}^{2}$ inertia connected to the wheel imitator through the gear of 10.5 ratio. Due to the gear, peak torque on the wheel at heavy braking approached $2000 \mathrm{Nm}$ and wheel angular speed $15 \mathrm{rad} / \mathrm{s}$. Aerodynamic and climbing factors were neglected in that study.

In Fig. 6, two braking diagrams obtained in [10] are shown: wheel velocities of the front left $(F L)$, front right $(F R)$, rear left $(R L)$, and rear right $(R R)$ wheels, appropriately, that follow the vehicle longitudinal velocity $v$ in Fig. 6 (a), and $\mathrm{EB}$ and FB wheel torque curves in Fig. 6 (b). As EB torque is not enough to retain optimal slip, the ECU requests additional FB torque. At the end of slowing down, recuperation turns off, and FB completes braking alone.
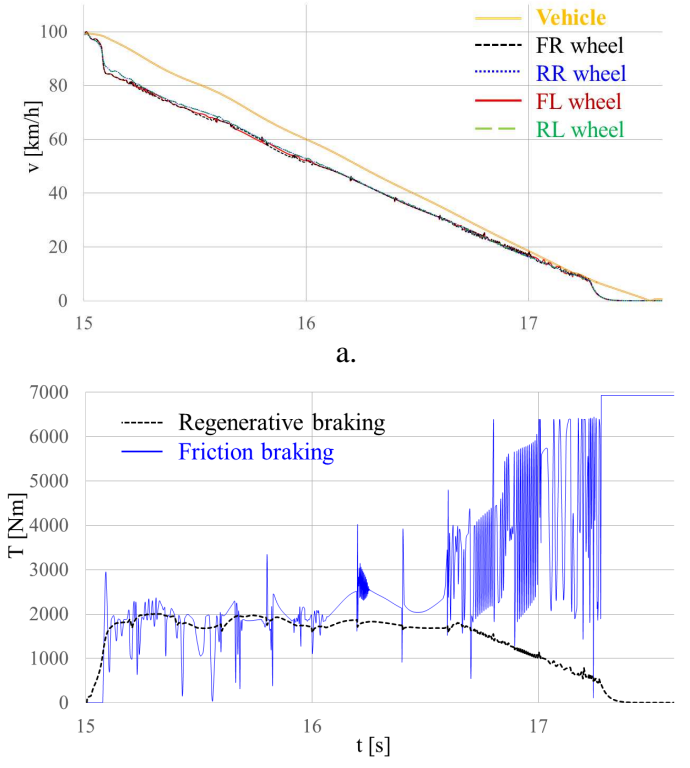

b.

Fig. 6. Hardware-in-the-loop experimental diagrams: a) vehicle and wheel velocities; $b$ ) torque.

Alongside the number of positive outcomes, the evident chattering phenomenon at low velocity is seen in the torque curves. In fact, three interconnected reasons may explain its appearance. First, increase of friction due to its static fraction in (6) when the vehicle moves slowly and several wheels tends to slip. Second, air friction (4) is ignored. Third, as at low velocity EB ceases and FB finalises braking alone, no torque stabilisation exists at that moment. Torque oscillations demonstrate that the simplified drive model used in [10] could not ensure proper torque adjustment. Such kind of oscillations, reported also by other researchers [8], [19], is a common issue of braking needed to be considered as it affects EV steerability and reduces energy recovery.

In Fig. 7, an improved Matlab ${ }^{\circledR} /$ Simulink $^{\circledR}$ model is proposed. Block Drive-U provides direct torque control, power supply, and recuperation. Together with Drive-I, it arranges the torque stabilisation loop with PI current controller. Blocks Drive-T and Drive-W belong to the speed loop shredded in heavy braking. Gear and vehicle inertia are represented by the PLANT block. Load is applied to the motor shaft from the LOAD block together with TF. Torque Allocation, FLC, and Slip Processing are the parts of ECU shown in Fig. 2. In turn, the application torque signal $T$ and vehicle velocity $v$ feed back the Slip Processing block to reflect slipping friction (6) and air friction (4). Motor angular speed $\omega$ and torque $T_{M}$ are used for recuperative power $P$ calculation (8). Just like in [10], no climbing is applied.

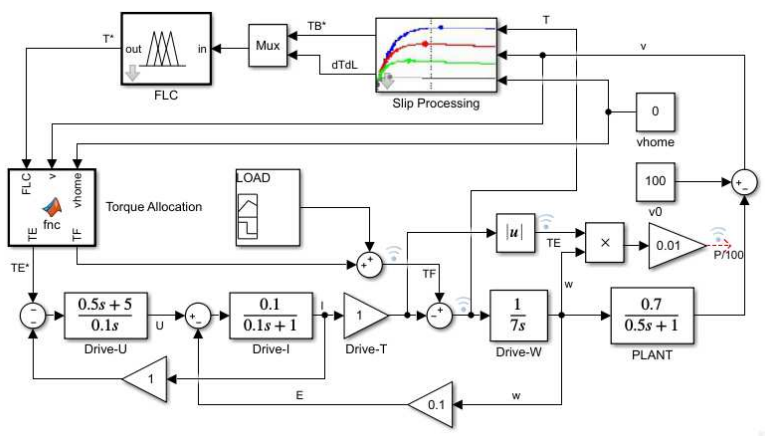

Fig. 7. Simulink model of the EV electric drive in the braking mode of operation.

As follows from Fig. 8, vehicle velocity ( $v$, green) drops from $v_{0}=100 \mathrm{~km} / \mathrm{h}$ in $3 \mathrm{~s}$.
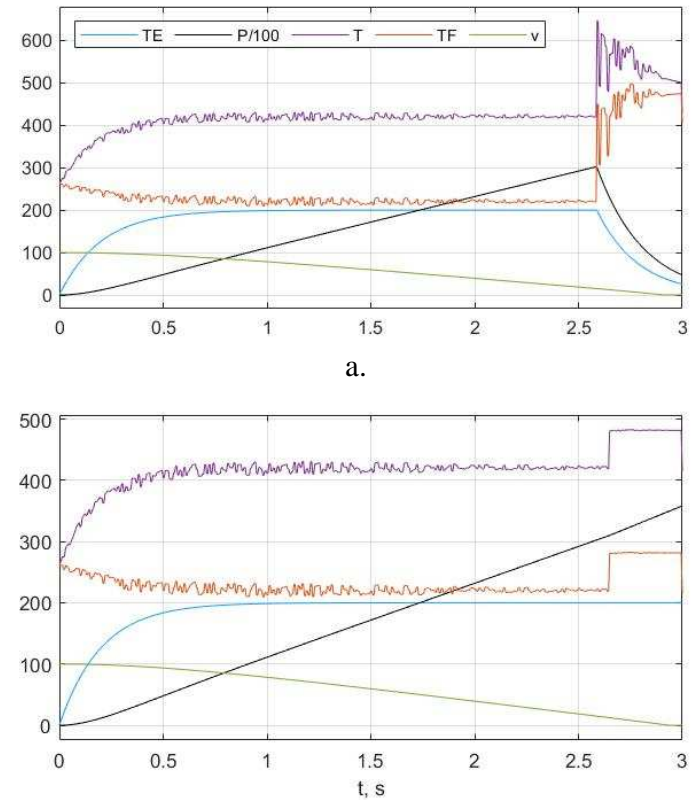

b.

Fig. 8. Braking diagrams obtained from the Simulink model without EB (a) and with EB (b) at low velocity.

Total braking torque ( $T$, purple) needed to ensure heavy stopping in response to driver's setpoint $T_{B}{ }^{*}=420 \mathrm{Nm}$ is obtained after allocation between motor $\left(T_{E}\right.$, blue) and friction $\left(T_{F}\right.$, orange) torque, wherein motor torque is restricted to $200 \mathrm{Nm}$. Torque oscillations are observed here mainly from FLC and reduce with velocity while converter switching is damped by the torque loop. In simulation, $100 \mathrm{~Hz}$ frequency was used for FLC processing at $200 \mathrm{~Hz}$ fundamental sample frequency. At low velocity $v_{\text {home }}=15 \mathrm{~km} / \mathrm{h}$, friction increases suddenly due to its static fraction. In Fig. 8 (a) EB turns off and 
torque begins oscillate intensively. In contrast, in Fig. 8 (b) EB persist in this case, recuperation does not interrupt, and no additional torque chattering is detected on the motor shaft. Based on the power curve $(P$, black) and assuming 50\% recuperative efficiency in (1), it turns out that nearly $22 \mathrm{~kJ}$ of energy is recovered during braking in the first case and $25 \mathrm{~kJ}-$ in the second one.

\section{Conclusion}

In the refined vehicle model, multiple factors are addressed, such as air resistance, road slope, and changeable friction. The improved motor and energy source model reflects the state of charge and electric current/voltage restrictions of the hybrid energy storage at various driving scenarios recognised by the tire model, such as smooth slowing and emergency antilock braking on different road surfaces. As a result, novel control arrangement is proposed, including fuzzy braking torque adjustment and stabilisation with torque allocation between electric and friction brakes thus integrating both friction and electric braking benefits. Obtained simulation diagram largely match the experimental curves. However, chattering of braking torque is reduced and evenly distributed throughout the braking process in the developed model.

\section{References}

[1] B. J. Varocky, Benchmarking of Regenerative Braking for a Fully Electric Car, Eindhoven University of Technology, Germany, 2011. 54 p.

[2] M. Shang, L. Chu, J. Guo and Y. Fang, "Hydraulic braking force compensation control for hybrid electric vehicles", International Conference on Computer, Mechatronics, Control and Electronic Engineering (CMCE), Changchun, China, 2010, pp. 335 - 339.

[3] S. M. Savaresi and M. Tanelli, Active Braking Control Systems Design for Vehicles, London: Springer, 2010, $254 \mathrm{p}$.

[4] S. Khastgir, "The simulation of a novel regenerative braking strategy on front axle for an unaltered mechanical braking system of a conventional vehicle converted into a hybrid vehicle", 8th International Conference and Exhibition on Ecological Vehicles and Renewable Energies (EVER), Monte Carlo, Monaco, 2013, pp. 1 - 6.

[5] F. Naseri, E. Farjah and T. Ghanbari, "An efficient regenerative braking system based on battery / supercapacitor for electric, hybrid, and plug-in hybrid electric vehicles with BLDC motor," IEEE Transactions on Vehicular Technology, v. 66, no 5, pp. 3724 - 3738. May 2017.

[6] Z. Chen, T. Lv, N. Guo, J. Shen, R. Xiao, X. Lu and $\mathrm{Z}$. Yu, "Study on braking energy recovery efficiency of electric vehicles equipped with super capacitor," Chinese Automation Congress (CAC), Jinan, China, 2017, pp. $7231-7236$.

[7] Y-B. Xie and S-C Wang, "Research on regenerative braking control strategy and Simulink simulation for 4WD electric vehicle", 2nd International Conference on Manufacturing Technologies (ICMT), Florence, USA, 2018, pp. $1-6$.
[8] H. Lin and C. Song, "Design of a fuzzy logic controller for ABS of electric vehicle based on AMESim and Simulink," 2011 International Conference on Transportation, Mechanical, and Electrical Engineering (TMEE), Changchun, China, 2011, pp. $779-782$.

[9] H. Jing, Z. Liu and J. Liu, "Wheel slip control for hybrid braking system of electric vehicle," International Conference on Transportation, Mechanical, and Electrical Engineering (TMEE), Changchun, China, 2011, pp. 743 746.

[10] A. Aksjonov, V. Vodovozov, K. Augsburg and E. Petlenkov, "Design of regenerative anti-lock braking system controller for 4 in-wheel-motor drive electric vehicle with road surface estimation," International Journal of Automotive Technology, vol. 19, no. 4, pp. 727 - 742, 2018.

[11] Brakes, Brake Control and Driver Assistance Systems: Function, Regulation and Components, K. Reif (Ed.), Friedrichshafen, Germany: Springer, 2014, 275 p.

[12] A. O. Kiyakli and H. Solmaz, "Modeling of an electric vehicle with MATLAB/Simulink," International Journal of Automotive Science and Technology, v. 2, no. 4, pp. $9-15,2018$.

[13] P. Spichartz, T. Bokker and C. Sourkounis, "Comparison of electric vehicles with single drive and four wheel drive system concerning regenerative braking," 12th International Conference on Ecological Vehicles and Renewable Energies (EVER), Monte-Carlo, Monaco, 2017 , pp. $1-7$.

[14] R. Pratap and A. Ruina, Introduction to Statics and Dynamics, Oxford University Press, 2002, 751 p.

[15] X. Zhang and H. Lin, "UAV anti-skid braking system simulation," 37th Chinese Control Conference, Wuhan, China, 2018, pp. $8453-8458$.

[16] S. Kadowaki, K. Ohishi, T. Hata, N. Iida, M. Takagi, T. Sano and S. Yasukawa, "Antislip adhesion control based on speed sensorless vector control and disturbance observer for electric commuter train AT series 205-5000 of the east Japan railway company," IEEE Transactions on Industrial Electronics, vol. 54, no. 4, pp. 2001 - 2008, 2007.

[17] M. Cecotti, J. Larminie and B. Azzopardi, "Estimation of slip ratio and road characteristics by adding perturbation to the input torque," IEEE International Conference on Vehicular Electronics and Safety (ICVES), Istanbul, Turkey, 2012, pp. $31-36$.

[18] H. Pacejka, Tyre and Vehicle Dynamics (3rd ed.), Oxford, UK: Butterworth-Heinemann, 2012, 672 p.

[19] M. Habibi and A. Yazdizadeh, "A novel fuzzy-sliding mode controller for antilock braking system," 2nd International Conference on Advanced Computer Control, v. 4, Shenyang, China, 2010, pp. $110-114$.

[20] M. Cerdeira-Corujo, A. Costas, E. Delgado, A. Barreiro and A. Banos, "Gain-scheduled wheel slip reset control in automotive brake systems," International Symposium on Power Electronics, Electrical Drives, Automation and Motion (SPEEDAM), Anacapri, Italy, 2016, pp. 1255 1260.

[21] Y. Tao, X. Xie, H. Zhao, W. Xu and H. Chen, "A regenerative braking system for electric vehicle with four in-wheel motors based on fuzzy control," 36th Chinese Control Conference, Dalian, China, 2017, pp. $4288-4293$. 